\title{
La educación a distancia como elemento del desarrollo en la sociedad del conocimiento
}

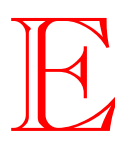

n el arranque del siglo XXI la so cie dad en ge ne ral ha sidotes tigo de los cambios que han generado la globalización de las economías, los desarrollos tecnológicos y los avances del conocimien to. En este con tex to, la sociedad delconocimien to implicano sólo el esclarecimiento de estos fenómenos sino también la previsión de soluciones que den respuesta social a las exigencias que suscitan tales asuntos. En el ámbito educativo la sociedad del conocimiento consideraal apren diza je como unaútil he rra mien ta que leper mi te al ciu da dano, a lo largo de su proceso de vida, desarrollar sus conocimientos intelectuales. En este escenario la educación a dis tan cia tieneunaposición privilegiada para explicar y comprender los desafíos que actualmente encaran los sujetos que confrontan los procesos generados por los actuales desarrollos y aplicaciones tecnológicas..

La tecnología ha transformando procesos y prácticas tradicionalesde la educación y la socialización del conocimiento mediante innovaciones que han modificado las formas de producción, distribución, apropiación, representa ción, significacióneinterpretacióndelain forma ciónyel conocimiento. En nuestros días, la educación a distancia tiende al uso cre cien te de tec no logías para ofre cerle a los su je tos del acto edu ca tivoun modelodeges tióncen tradoenla comunica ciónyen elapren dizaje. Esto implica fomentar el estudio independiente y grupal, y la interacción académi caefec tiva en trelos ac to res del apren dizaje, máslautiliza ción de diversos canales de comunicación, entre los cuales predomina Internet, pues facilita tal comunicación y conlleva una tendencia hacia la generación de escenarios virtuales de aprendizaje.

Por esta razón Internet representaunarealidadtecnológicarelevante en el diseño de propuestas educativas virtuales para cualquier disciplina y por ello resulta conveniente tomar en consideración diversos aspectos tanto de su desarrollo como de su aplicación en la educación de este siglo. 
Es, pues, indispensable que la educación virtual estudie las repercusiones del aprendizaje a través de las redes de comunicación, las pro pues tas teó ricas que se dis cu ten ac tualmen te en rela ción con la interactividad y la navegación, ylas pers pectivas socialeseins titucionales que se espera de todo eso en el siglo XXI. Mientras tanto la sociedad del conocimiento, como una expresión de la globalización, ha producido cambios sustanciales dirigidos al ejercicio profesional y construido escenarios de vinculaciones, relaciones y acciones que afectan a la sociedad en su conjunto, y al mismo tiempo, ha generado re tos para la edu ca ción a dis tan cia fren te a las nuevas rea li da des in formativas y tecnológicas.

La comunicación educativa, la interacción y el diálogo académico constituyen la base sobre la cual se sustenta el éxito o fracaso de toda propues taeduca tiva a dis tancia. Encon secuen cia elpapel del tu toracadémico es decisivo para orientar los procesos cognitivos, cuestionar los diversos pun tos de vis ta, suge riral terna tivas de aprendizajeeidentificar la información relevante que apoye el aprendizaje.

Al mismo tiempo el creciente uso del conocimiento tecnológico como instrumento del desarrollo económico ha generado necesidades educativas relacionadas con la formación de los sujetos para hacerlos competen tes enla aplicación delco nocimien to tec nológicoy enlaoperación delos proce sos de riva dos de dichoco nocimien to.'Todoloan terior vuelve necesario el hecho de incidir en el desarrollo de tareas de gestión educativa a distancia que incluyan aprendizaje innovador, formacióndeau tores decon teni do, tu tores preparados paralain teracción en línea y abatimiento de costos.

No obstante la cre en cia de quela edu ca ción a dis tan cia pue de ser un paraíso para la autoformación, hay que considerar que este tipo de enseñanza somete a los actores del acto educativo a normas pedagógicas que garanticen la validez, la calidad y la efectividad de su aprendizaje. Asimis mo cabe resal tarelhe cho de que han surgi do co rrien tes pedagógicas enlas que convergen pos turas mul tidis ciplinarias orien ta das al diseñodemodeloseducativos, desarrollodecontenidos, modelosdeinstrucción y aplicaciones tecnológicas.

Por otra parte la enseñanza a distancia se vincula con la gestión del conocimiento sustentado en redes teleinformáticas con el doble propósito de colaborar en la construcción de conocimiento y de socializar los aprendizajes. En consecuencia, dicha enseñanza exige la participación de suje tos com prometidos conla ob servan cia deme to dologías de 
aprendizaje, métodos de investigación y manejo de estrategias de búsquedas bibliográficas.

Tam bién se ad vier te queel cons tan te de sa rrollo de la cien cia y la tecnología en las diversas áreas profesionales ha propiciado una acelerada generación de conocimiento, situación que dificulta su estudio permanente ennivelesóptimos de apren dizaje. Eneste sen tidosepercibeque los fenómenos surgidos con las tecnologías y los requerimientos del merca dola bo ral han dadolugarala forma ción de pro fe sio nales de alto nivel. Al mismo tiempo se ha generado el requerimiento de incidir en una mejorpreparación delos re cursos humanos, los cuales pro piciado por la orientación hacia lo global, a democratizar la educación, a la cons tan tegeneración de re cur sos documentales yaincremen tarlas posibilidades que otorgan los desarrollos tecnológicos.

Se tra ta pues de asun tos quelas dis cipli nas de ben aten der pues to que se requiere de información relevante que satisfaga los intereses de los actores del aprendizaje. Se precisa, pues, que el desarrollo de sistemas de información se adecue a la interactividad en línea y a los intereses educativos a distancia.

En los medios bibliotecarios se ha pretendido atender esta tarea principalmente de manera presencial a través de licenciaturas, maestrías, doc to rados, diplo ma dos y cur sos cor tos de ac tualiza ción. Sinembargo, se advierte que actualmente las propuestas educativas a distancia vinculadas con la bibliotecología son escasas y en algunos países latinoamericanosinexistentes. Laproblemáticaqueplantealaenseñanza a distancia de la disciplina se incrementa frente a la evolución constante de las tecnologías de información y comunicación y ante la demanda creciente por parte de los sectores bibliotecarios sobre propues tas edu cativas que aborden fenó me nos emergentes. Porellose hacenecesa rio in ci diren la bús que da de un modeloedu ca tivo queconcuerde con las características de lejanía y situación laboral de los alumnos potenciales. Así pues, por las características que lo definen, el modelo de la educación a distancia puede ser el idóneo para sustentar el diseño de propuestas educativas en el campo bibliotecológico en sus distintos niveles.

Después de los años noventa la educación a distancia se ha vinculado de manera estrecha con el uso de tecnologías de información y comunicación, y con el desarrollo de medios didácticos para difundir información y conocimiento, procesos de cambio tecnológico que han contribuido a transformar la sociedad del conocimiento. Así, en este 
tipo de sociedad la educación virtual se ha situado en las redes de comunicación y su escenarioes elciberes paciointeractivoycomunitario. Laapariciónydesa rrollo de estenuevo con tex to propicialage neración de programas educativos complejos en bibliotecología en los que la construcción de conocimiento entre los actores del proceso educativo se perfila comola principal poten cialidady el nue vo de sa fío. Asimismo la penetración de las tecnologías de información y comunicación han propiciado que la vigencia de los conocimientos disciplinares sea cada vez más corta, situación que necesariamente redunda en los procesos de formación y en el ejercicio de la profesión bibliotecológica.

Frente a los nuevos desafíos la bibliotecología requiere diversificar su campo de conocimiento y desarrollar nuevas alternativas de formación tomando en cuenta los avances recientes del conocimiento en el área. También habrá de tomar en cuenta las demandas del mercado laboral e incorporar el uso de tecnologías de información y comunicación para producir y difundir nuevos conocimientos, innovar sus métodos y técnicas de enseñanza-aprendizaje y continuar desarrollando tanto la investigación básica como la aplicada con el propósito de incrementar la formación de recursos humanos con un alto nivel de especialización y capaces de elaborar estudios específicos y de amplio espectro que reflejen las necesidades informativas de las sociedades usuarias en forma local y nacional, y de proyectar sistemas de información que contemplen el máximo aprovechamiento de las tecnologías y los recursos documentales del país del que se trate. 